\title{
From the Editor of Sexuality and Disability: A New Start and a New Beginning Built Upon the Past
}

\author{
Sigmund Hough ${ }^{1}$
}

Published online: 1 February 2016

(C) Springer Science+Business Media New York 2016

We are not able to start without acknowledging a beginning and a past. This past year has been a successful year for the journal. A journal which continues to build upon its first issue towards advancement in knowledge, enlightenment and communication. We appreciate the leadership and staff at Springer for supporting our scope and mission. We so much appreciate and respect the Editorial Board Members and Peer Reviewers for all their dedication, hard work and commitment to the issues related to sexuality and disability/ ability. Those who have contributed to the literature received a special recognition for their determination and focus to scholarly inform and academically educate. Congratulations for 2015, as we continue together in 2016. And so we continue...

The journal of Sexuality and Disability remains a professional home for many, and a place of professional rejuvenation and exploration for still more. If you are new to the journal, we give to you a "BIG WELCOME" to participate as a reader, author, academician, clinician, educator, service provider, researcher, advocate, and individual or individuals seeking information. Over decades of contribution to the literature on sexuality and disability, we have been a part of the growth and understanding. Now most importantly, we continue to be a part of change in how we look and examine the topic, the need, and the response in terms of best practice- evidence based approaches. With the intelligence, experience, motivation and commitment from our authors, readership, peer reviewers and editorial board, and resources with guidance from the Springer Staff, our journal's mission continues to be strong and meaningful.

Sexuality and Disability continues to provide original impact articles addressing the mental health and medical aspects of sexuality in relation to rehabilitation, hospital, academic and community settings, publishing up-to-date articles, case studies, clinical practice reports, reviews, featured articles, historical articles, special grand rounds topics, brief research reports and survey data reports. Value benefit is provided to authors through

Sigmund Hough

Sigmund_Hough@hms.harvard.edu

1100 Cummings Center, Suite 207, Beverly, MA 01915-6144, USA 
worldwide electronic exposure and professional access, while readership gains from scholarly contributions to advance the field through research, best-practice and educational articles. The refined lens of individual contributions from the local and international community continues to deliver a wealth of information on the topic of sexuality and disability for the reader. Thank you for joining our professional community. 